\title{
EDITORIAL
}

\section{The Social Science Research: Application of Practice}

\section{Chia-Huei Wu*}

Department of Hotel Management and Culinary Creativity, Minghsin University of Science and Technology, Hsinchu 304, Taiwan, China

\section{ARTICLE INFO}

Article history

Received: 7 April 2021

Accepted: 7 April 2021

Published Online: 9 April 2021

This regular issue of the Macro Management \& Public Policies collects six articles.

The paper, titled Quality of Papers Stems from Authors and Quality of Teaching Stems from Professors, constructed the "SPQR Principle" (Semper Paratus ad Qualitatem et Rationem) to analyse papers, books and teaching. After researching cases from PRT Journals and teaching documents, the author found that the quality of papers is obviously related to the quality of journals. High quality papers are published only in "Peer Reviewed Trusted Journals (PRTJ)", while low quality papers are published in the "Predatory Publishing Journals". But it is not correct. This paper shows that the quality of papers depends on the quality of the authors and we should pay more attention to the two sides of the "publishing medal": authors and professors.

The paper, titled Determination of Business Strategies Using SWOT Analysis; Planning and Managing the Orga- nizational Resources to Enhance Growth and Profitability, tried to provide some basic research for the SWOT and several practical insights of steps to provide a matrix. SWOT has a long historical background, and the results can be expressed by a matrix which contains four factors: strengths and weaknesses, opportunities and threats faced by the company. The analysis combines the internal and external of the organization, its own strengths and weaknesses, environmental threats and opportunities, which can effectively help enterprises achieve the current goals. Although this method has some shortcomings, it can help enterprises to formulate future strategies.

In the paper, titled Population Change vs Natural Geography in Asia: A Sociological Appraisal, intended to investigate the environmental and social problems caused by population change. In Asian countries, population change is a more positive phenomenon. And in this area,

*Corresponding Author:

Chia-Huei Wu,

Department of Hotel Management and Culinary Creativity, Minghsin University of Science and Technology, Hsinchu 304, Taiwan, China;

Email: chiahuei530@gmail.com 
the mismatch between population growth and external carrying capacity has brought many problems. With the advancement of urbanization and the influx of a large number of people, the new lands are overpopulated while the old are under populated. Moreover, the population explosion in a short period of time has also brought about environmental and pollution related problems. This kind of change has brought complex consequences, which is worthy of scholars' research.

The paper, titled Human Rights and Social Justice through Open Educational Resources and Lifelong Learning, examined how the promise of resilient, sustainable quality open education. In the context of sustainable development and education for all, OER (Open Education Resources) was adopted in 2019. It includes five aspects: building capacity and using OER; formulating supportive policies; ensuring effectiveness; promoting the establishment of sustainable OER model; promoting international cooperation; monitoring and evaluation. In today's society and the global epidemic of COVID-19 in 2020, OER involves human rights and social justice, and the proposal will become a catalyst for the realization of several other sustainable development goals, so it is vital.

The paper, titled A Comparative Study of Humanistic Exchange and Cooperation between China and Southeast
Asian in the Perspective of "the Belt and Road" Initiative, describes and discusses the China-ASEAN strategic partnership. Nowadays, the communication between countries in the world is no longer just economic exchanges, and the interaction between cultures has become the mainstream. After studying the cases of Confucius Institute, sister cities and tourism cooperation, the paper found that the cultural exchanges between China and Southeast Asia had a long history. Under the Belt and Road, China and Southeast Asian countries are more closely connected through the ancient maritime Silk Road. This has further consolidated the strategic partnership between China and ASEAN, and also provided a reference for building a community of shared future for mankind.

The paper, titled A View of Beijing's Traffic Policy: Evaluation on the Policies Released in 2010 to Ease Traffic Congestion, the author paid attention to the traffic policy and Beijing traffic. Because of the developing economy and the process of urbanization, many cities in China face the problem of traffic, especially Beijing. The author takes it as an example, researched the number of cars during the end of 2005 to the end of November 2010. He found that motor vehicles in Beijing increased from about 2.58 million to about 4.69 million. The problem of traffic affects the daily lives of the residents. 